\title{
LA CONCIENCIA DE LINAJE A TRAVÉS DE LA REPRESENTACIÓN HERÁLDICA: EL EJEMPLO DE LA FAMILIA RIQUELME (SS. XIII-XV)
}

\author{
Manuel Pérez García*
}

\section{RESUMEN}

En el presente artículo realizamos un breve recorrido sobre la génesis de la construcción del lustre y distinción social de los viejos linajes nobiliarios mediante lo que la historiografía ha denominado «cultura material y simbólica». A partir de la misma se empieza a edificar la memoria de tales linajes y apellidos que vinieron del Norte de Castilla y se instalaron en el Reino de Murcia participando en la última fase de la Reconquista frente a los musulmanes del Reino nazarí de Granada. Así, y en torno a la figura mítica del fundador del linaje, que es el primer miembro instalado en el Reino, se instalan las bases del poder y prestigio social que la familia disfrutará generación tras generación. Mediante fuentes históricas de gran valor como pueden ser las crónicas, memoriales, genealogías y la heráldica, presentamos de forma sumaria, y a través del ejemplo del linaje Riquelme, cómo mediante dichos elementos materiales la familia en sucesivas generaciones irá perpetuando la memoria y conciencia del linaje con el fin de consolidar su estatus social dentro de la oligarquía.

Palabras clave: Linaje, familia, cultura material, heráldica, poder, prestigio social, memoria.

\begin{abstract}
In this article we analyse briefly the genesis of the building up of glory and social distinction of oligarchy through the material sources, which was called «material and symbolic culture» by historiography and constituted a constant feature of old lineages belonging to nobilty. From the point of view of such culture, a lineage memory was constructed, which belonged to the main surnames and lineages that fought against muslims of nazari Kingdom of Granada during the last period of the Reconquest. In that way, around the mythical figure of the founder of the lineage, who was the first member settled in the Kingdom, the bases of his power and social prestige began to be installed, lasting throughout consecutive gene-
\end{abstract}

* Miembro del Seminario Familia y elite de poder en el Reino de Murcia (ss. XV-XIX), Departamento de Historia Moderna, Contemporánea y de América (Facultad de Letras). Universidad de Murcia. 
rations. Based upon important historical sources such as chronicles, memorials, genealogies and the heraldry, we introduce briefly, through the example of Riquelme lineage, how the family, using such material elements, perpetuated his memory and «lineage self-awareness» in order to consolidate their social status within the oligarchy.

Key words: Lineage, family, material culture, heraldry, power, social prestige, memory.

\section{ALGUNAS CONSIDERACIONES SOBRE LA CONSTRUCCIÓN DE LA MEMORIA HISTÓRICA DEL LINAJE}

El rey Alfonso X el Sabio exponía en Las Partidas: «Hidalguía es nobleza que le viene a los omes por linaje» ${ }^{1}$. Es decir, las familias más destacadas de la Castilla bajomedieval en un primer momento van a ir reforzando la concepción mental de familia a través del sistema de apellidos y de la onomástica. Junto a ello aparece la figura del fundador del linaje, de la que parte el tronco común del mismo, siendo el antepasado glorioso a través del cual se construye un pasado mítico y alegórico que dota al propio linaje de lustre y honor.

De las glorias y hazañas míticas del «fundador del linaje» serán por las que presuman sus sucesores, durante toda la Edad Moderna, con el fin de que no se borre de la memoria colectiva los buenos actos que para el común realizaron estos «insignes hombres». Pertenecientes, todos ellos, a la oligarquía murciana, los cuales contribuyeron al bien de la comunidad participando en la Reconquista y recuperando el suelo murciano de manos del «infiel», del Islam, ayudando a la cristianización y glorificación del Reino.

Es por ello, que las colecciones documentales de nobiliarios son redactadas en época Moderna para ayudar a que no se olvide y se fije en la memoria colectiva ese pasado glorioso de ciertos linajes y familias que contribuyeron a recuperar el Reino de Murcia de manos del Islam.

Este tipo de documentación la debemos cruzar con otro tipo de fuentes ${ }^{2}$, es decir, con textos narrativos como es el caso de las crónicas; que como veremos, para la época del reinado de Alfonso XI son de suma importancia. En palabras del medievalista francés G. Duby este tipo de fuentes, los nobiliarios, en muchos casos constituyen fuentes inéditas ${ }^{3}$,

1 Partida II, Título XXI, Ley IIII.

2 Sobre la metodología a emplear sobre este tipo de fuentes ver CHACÓN JIMÉNEZ, F., «Aproximación y notas metodológicas para el estudio de la familia en Castilla durante la Baja Edad Media. Algunos ejemplos murcianos», Homenaje a Juan Torres Fontes, Murcia, 1987; y del mismo autor, «Población, familia y relaciones de poder. Notas y reflexiones sobre la organización social hispánica: circa s. XV-circa s. XVII», en Historia y perspectivas de investigación. Estudios en memoria del profesor Ángel Rodríguez Sánchez, RODRÍGUEZ CANCHO, M. (coor.), Colección Documentos/Actas, pp. 85-93.

3 El Nobiliario de los Riquelme que hemos empleado para la realización de este estudio podríamos catalogarlo de inédito. Debido a que tanto dicha fuente manuscrita extraída del Archivo Municipal de Jerez, como el Cartulario Real del Archivo Municipal de Murcia, que tenemos del s. XVIII en donde aparecen el origen y noticias genealógicas de los Riquelme de Murcia, no aparecen en ninguna referencia bibliográfica. Ver los tra- 
y junto con los relatos genealógicos de época medieval «son la base documental para los estudios sobre la conciencia de parentesco y linaje» ${ }^{4}$.

Este mismo autor señala que la preponderancia de la línea agnática contribuyó a la progresiva implantación de los linajes en el Occidente medieval. Dicha implantación alcanzará un gran desarrollo durante los siglos XII y XIII.

Esta idea queda perfectamente expresada a través de las fuentes literarias. El primer gran poema épico no aparece hasta finales del s. XII y principios del XIII: el Cantar de Mio Cid. Como todo cantar de gesta y obra caballeresca, ayuda a enraizar en la conciencia individual el ideal nobiliario y, por tanto, a ir fijando el concepto de linaje.

Esta conciencia, si cabe, adquirirá más fuerza con los dos códigos alfonsinos (el Fuero Real y el Fuero Viejo de Castilla) y con la obra literaria de Don Juan Manuel. En las Obras Completas de Don Juan Manuel se menciona el término de linaje en donde se muestra un claro deseo de vanagloriar al cabeza o jefe de dicho linaje:

«La segunda manera de amor de linage, es quando [ vn ] omne a linage con otro [ et ] conviene quel ame por el linage, [ et quando el linage ] es mayor et mas acercado, tanto deve ser el amor mayor. Et este nombre del linage es sacado [ de linna ], ca linage quiere dezir tanto como linna de generación.» 5

El linaje, finalmente, no va a representar otra cosa que una construcción mental y organizada en torno al parentesco, a la sangre y a la memoria, necesita materializarse ${ }^{6}$. El linaje arropa culturalmente a quien lo posee. Esta idea queda reflejada por el cronista real Fernando del Pulgar, en aquel mundo en que todo tenía un origen divino, quien hacia 1490 expresó que: «Dios fizo homes e no fizo linages» 7 .

Esta construcción de memoria común, de crear una imagen mítica, no representa si no la necesidad que la nobleza europea tenía de ella para hacer un uso social de dicha memoria ${ }^{8}$.

bajos que se han hecho sobre los Riquelme o en donde aparecen noticias suyas: MARTÍNEZ CARRILLO, M ${ }^{\mathrm{a}}$. DE LOS LLANOS, «Reconstrucciones familiares a través de documentos concejiles: los Riquelme murcianos», en MONTOJO Y MONTOJO, V. (ed.), Linaje, familia y marginación en España (ss. XIII-XIX), Seminario de Familia y elite de poder en el Reino de Murcia (ss. XV-XIX), Universidad de Murcia, 1992; DE LA VALGOMA Y DÍAZ-VALERA, D., Los Saavedra y los Fajardo en Murcia, Academia Alfonso X el Sabio, 1957, Murcia; FONTES FUSTER, E., Nuestra Heráldica (Historia de la familia Fontes y otras enlazadas con ella), Murcia, 1936, caps. V, VI, XX.

4 DUBY, G., «Estructuras de parentesco y nobleza en la Francia del Norte en los siglos X y XI», Hombres y estructuras en la Edad Media, Madrid, 1977.

5 Don Juan Manuel, «Libro Endefido», Obras Completas, p. 184. Ver también el «Libro de las Tres Razones» y el «Libro de las armas».

6 HERNÁNDEZ FRANCO, J., «Consideraciones y propuestas sobre linaje y parentesco», en Familia, parentesco y linaje (CASEY, J. y HERNÁNDEZ FRANCO, J. eds.), Universidad de Murcia, 1997.

7 Crónica de los Reyes Católicos (Edc. a cargo de Juan de Mata, Madrid, 1963, pp. 367.

8 Ver la obra de BURKE, P., «The representation of shel in the Renaissance portrait», en id. The historical anthropology of early modern Italy. Essays on perception and communication, Cambridge University Press, 1987. 
Así, esta nobleza va a estar imbuida de una «cultura genealógica» ${ }^{9}$ y de una «cultura del linaje» que va construyendo a través de la memoria histórica ${ }^{10}$.

Esta «cultura de linaje» que se va fomentando a través de un imaginario mental colectivo va a tener una clara representación material. Hemos señalado por una parte las fuentes literarias, entre las que destacan las crónicas y relatos, y por otra, los nobiliarios, que ayudan a que la memoria histórica del linaje no se pierda.

Pero igualmente se ayuda a reforzar dicha memoria a través de la representación de las hazañas del linaje en los escudos de armas y blasones que van a adornar las fachadas de los palacios y casas señoriales de las familias más distinguidas. Presumirán durante toda la Edad Moderna de un pasado glorioso, especialmente de la participación de muchas de ellas en la Reconquista, y que mejor aval que el blasón como imagen en donde se materializa dicho pasado.

Los emblemas heráldicos van a ser una importante carta de presentación nobiliaria ${ }^{11}$.

\section{EL EJEMPLO DEL LINAJE DE LOS RIQUELME}

Muestra de ese antepasado común y del que todos los miembros de la familia en la Edad Moderna lo tenemos en Guillén Riquelme: primer miembro del linaje Riquelme que tenemos datado en el Reino de Murcia.

Tenemos varias noticias sobre el origen del apellido. El Manuscrito Riquelme ${ }^{12}$ menciona que proviene del gran Reino de Francia de la casa de los Monforts, señores y condes de Tolosa. Procedentes del castillo de Rodelas (ciudad de la Rochela), vinieron en ayuda de D. Pelayo ricos hombres de Francia y Alemania, entre ellos bajó D. Guillén de Monfort:

«diole el Ricoîelmo por armas i diole un solar en el que sucedió la batalla que hoy se llama del Ricoîelmo que esta cerca del valle del castillo de Maderuelo y hay un lugar llamado Riquelme por la memoria de esta batalla. Fue su capitan de los vizcainos y tuvo un hijo que fue Pedro Guilen de Monfort.»

Por este motivo en el escudo de armas de los Riquelme aparece un yelmo. El escudo es de campo de gules en donde se destaca un yelmo con un brazo que lo tiene del penacho del cimero. Así, aparece la celada símbolo de la defensa como arma que cubre la cabeza que representa la vida y lo restante del escudo corrobora el mérito de esta familia ${ }^{13}$.

9 SPIEGEL, G., «Genealogía: Form and Function in Medieval Historical Narrative», en History and Theory, 22, 1983.

10 YATES, A. FRANCES, El arte de la memoria, Madrid, 1974.

11 Entre los estudios de heráldica murciana destacan: Cehegín: repertorio de heráldica de la Región de Murcia (coord. GONZÁLEZ BLANCO, A.), Murcia: Editora Regional, Cehegín: Ayuntamiento, 1990, 265 pp.; VELASCO DE LA PEÑA, C., Murcia: Escudos del Archivo Municipal de Murcia, Murcia: editora regional, 1992, $227 \mathrm{pp}$.

Igualmente remitimos a la obra de MENÉNDEZ PIDAL DE NAVASCUES, F., «Le début des emblemes heraldiques en Espagne», Armas e Troféus, V Serie, tomos III e IV, Lisboa, 1984.

12 Archivo Municipal de Jerez (A.M.J.), Fondo Soto Molina, L. 17, E. 306: Noticias y antecedentes genealógicos de la familia Riquelme de Murcia, s.a. [ s. XVII ? ]; manuscrito anónimo / M. / 6 hojas.

13 Archivo Municipal de Murcia (A.M.M.), Diario de Cartas Reales, Sig. 858, 1769, fols. 19v.-22r. 
Esta representación de la celada queda recogida por el cronista Cascales ${ }^{14}$ conforme a lo que dijo en la Antigüedad Virgilio:

«Umun pro cunctis dabitur capuz», y «pro capite pugnare», es frase proverbial para decir la defensión de la vida: y cubrir con la celada la cabeza, es defender nuestra vida con las armas. La celada fue la principal arma de Palas, y de Marte, Diosa y Dios de la guerra.»

El dicho Guillen Riquelme, descendiente de Guillen de Monfort, entró en Murcia en el año 1265 participando en la conquista del Reino ${ }^{15}$ :

«Guillen Riquelme entro ganando aquella ciudad...quedo heredado en ella por el rey Alfonso X el Sabio entre los 323 ilustres caballeros pobladores como aparece en dicho Libro a hoja 4 ...se hallo en la toma de la ciudad de Orihuela, villa de Lorca...y tuvo repartimiento como parece de sus archivos y libros de población. Fue regidor de Murcia y procurador de Cortes. En dichas Cortes se trato de echar de la Casa Real al Conde D. Alvar Nuñez de Lara.

Cuando el rey D. Fernando pupilo, entonces rey de Aragon D. Jaime II le usurpo este reino de Murcia y entonces el rey de Aragon echo de Murcia a todos los caballeros que seguian la labor del rey D. Fernando el cual cuando mayor bajo a restaurar su Reino de Murcia trajo en su compañia a Guillen Riquelme por su capitan mayor de ejercito...entro el rey en Murcia y luego mando restituir los bienes a Guillen Riquelme.»

Muchas de estas noticias entran dentro de ese pasado alegórico, que constantemente se trata de rememorar, por lo que estos datos deben ser tomados por el historiador con suma cautela. El discernir entre lo real y lo ficticio constituye una difícil tarea para el mismo.

Tras la firma de la sentencia de Elche-Torrellas en 1304 y con la restitución de los bienes incautados por los aragoneses a los castellanos, entre ellos como hemos visto a Guillén Riquelme ${ }^{16}$, comienza el desarrollo efectivo de la vida socio-política del linaje en el Reino de Murcia.

Así, el linaje Riquelme queda constituido en su génesis por la actividad guerrera, que lo dota, tanto a este como a otros muchos linajes, de un espíritu de constante beligerancia.

Recordemos que el Reino de Murcia constituía la frontera entre el Cristianismo y el Islam, al estar situado frente al Reino de Granada.

Esta actividad y espíritu guerrero va a tratar de ser potenciado por el monarca Alfonso $\mathrm{XI}$, quien trata de resucitar los ideales de caballería, que según él, tal y como relata en sus crónicas $^{17}$, se habían perdido.

14 CASCALES, F., Discursos históricos de la Ciudad de Murcia y su Reino, Academia Alfonso X el Sabio, Murcia, 1980, p. 476.

15 A.M.J., Fondo Soto Molina,....

16 Guillén Riquelme y otros miembros de su familia habían recibido donaciones de tierra en las particiones $3^{\mathrm{a}}, 4^{\mathrm{a}}$ y $5^{\mathrm{a}}$ de los repartimientos efectuados por Alfonso X el Sabio. Ver TORRES FONTES, J., Repartimiento de Murcia, CSIC-Academia Alfonso X el Sabio, Murcia, 1960.

17 Gran Crónica de Alfonso XI, ed. de D. CATALÁN, (1976), Madrid. Vol. I, pp. 369-70. 
Así, este monarca va a tratar de reemprender la conquista, la cual se hallaba paralizada. Pero se encontró con la falta de efectivos en sus tropas, por lo que en el Ordenamiento de Alcalá de 1348 estableció la obligación, para todo el reino, de mantener caballos y armas según la cuantía de los bienes ${ }^{18}$.

De esta forma se va a armar a la caballería villana , constituyéndose el cuerpo social de caballeros de cuantía, dentro del estamento nobiliario, que se van a ir asimilando socialmente al sector más elevado de la nobleza. Podemos pensar que los Riquelme podrían estar dentro de la categoría social de caballería villana, ya que la cantidad de lotes de tierra que recibieron en los repartimientos de Alfonso X no fue muy elevada. Solamente encontramos entre ellos un solo caballero, Guillen Riquelme, mientras que el resto eran peones ${ }^{19}$.

El Adelantamiento de Murcia hace que el individuo se dote de un espíritu guerrero por ser una zona de inestabilidad y de constantes luchas ${ }^{20}$. Se constituye una «ideología guerrera ${ }^{21}$ que hace que se produzcan procesos de movilidad social por parte de miembros de estos linajes. Los servicios a la Corona que realiza el linaje Riquelme, en sus luchas contra los musulmanes, en la frontera con el Reino nazarí de Granada, hace que el status social del mismo vaya in crecendo, dotándose, por tanto, el grupo familiar de un gran prestigio $^{22}$.

Ejemplo claro de ello es Martín Riquelme, llamado «el valeroso» por los Reyes Católicos por los méritos y servicios que realizó a favor de la corona castellana, siendo nombrado adelantado del Reino de Murcia $^{23}$.

«Martin Riquelme fue paje de D. Fernando y la reina Isabel, sirvioles en alegría del adversario de Portugal, fue copero mayor suyo, capitan de lanzas en la toma de la ciudad de Alhama, en la villa de Aledo en 1488... se enfrento a 60 moros... y les quito tres banderas.»

Así, entrado el s. XVI, y finalizada la Reconquista, con la toma de Granada, el linaje de los Riquelme presenta sus credenciales como grupo que ha participado en la lucha final

18 GARCÍA DÍAZ, I., «La política caballeresca de Alfonso XI», Miscelánea Medieval Murciana, vol. XI, 1984.

19 MARTÍNEZ CARRILLO, Ma DE LOS LLANOS, Ob. Cit., 1992. Ver igualmente de esta misma autora, «El padrón de cuantiosos murcianos de 1374», Miscelánea Medieval Murciana, XL, 1984; y el artículo de VEAS ARTESEROS, F., «Dinámica del Concejo de Murcia (1420-1440), Miscelánea Medieval Murciana, IX, 1982.

20 Destacan las luchas nobiliarias entre bandos durante la Baja Edad Media que han sido estudiadas por MARTÍNEZ CARRILLO, Ma DE LOS LLANOS, Manueles y Fajardos. La crisis bajomedieval en Murcia, Academia Alfonso X el Sabio, 1985. Ver también los artículos de TORRES FONTES, J., «Los fronterizos murcianos en la Edad Media», Murgetana, $n^{\circ}$ 100, 1999; HERNÁNDEZ FRANCO, J. y JIMÉNEZ ALCÁZAR, J..F., «Estado, aristocracia y oligarquías urbanas en el Reino de Murcia. Un punto de flexión en torno a las comunidades de Castilla», Chronica Nova, 23, 1996, pp. 171-187; SORIA MESA, E., «La nobleza de Lorca en la Edad Moderna: un grupo de poder en continua formación», Murgetana, XCV, 1997.

21 RODRÍGUEZ LLOPIS, M., Historia de la Región de Murcia, Dirección General de Cultura, Biblioteca Regional de Murcia y Editora regional de Murcia, Murcia, 1998.

22 PÉREZ GARCÍA, M., «Servicios en la frontera: el apogeo del linaje Riquelme (ss. XIII-XVI)», en Actas del Congreso Abadía: V Jornadas de Historia (Iglesias y Fronteras: Congreso-Homenaje a José Rodríguez Molina), Alcalá la Real (Jaén), 2004, pp. 613-620.

23 A.M.J., Fondo Soto Molina,.... 
contra los musulmanes. El linaje presumirá durante los siglos XVI, XVII y XVIII que ha participado en la Conquista de Murcia y en la victoria final frente al Islam, presumiendo de ser cristianos viejos.

Esto se va a materializar, como hemos señalado anteriormente en una cultura material, mediante la representación de estas hazañas en blasones y escudos de armas que adornan sus casas señoriales y palacios.

Así, en el centro de la fachada del palacio Riquelme ${ }^{24}$ aparece el escudo de la familia, que hemos detallado anteriormente. Se encuentra en la calle Jabonerías situada al final de la calle Platería cerca de la Plaza de San Bartolomé ${ }^{25}$. Va a ser ejecutada en el último tercio del s. $\mathrm{XVI}^{26}$. En 1612 se va a remodelar, cosa que se menciona en la escritura de ejecución por D. Luis Riquelme, miembro de la Orden de Santiago, y por el cantero Bartolomé Sánchez, en donde se dice en el contrato que la remodelación de la escalera, la cual era de piedra, tiene que ser de piedra buena y de calidad.

El escudo además de tener el emblema del hábito de Santiago (cruz) tenía que atenerse a los escudos de la familia, en unos reposteros (grandes tapices labrados en lana que utilizaban las grandes familias). Estos salvajes que vemos representados medían de $2 \mathrm{~m}$. y poco más. Las columnas de la puerta son columnas torsas (se cortan a la mitad de la puerta). La casa estaba sobremontada en una galería y estaba desmochada. Los salvajes representan la «vigilancia permanente» frente al infiel y al invasor. Son la representación simbólica del espíritu bélico del Adelantamiento de Murcia como frontera frente al Islam.

Como vemos los elementos y las alegorías bélicas aparecen en las representaciones materiales y artísticas de los linajes murcianos que participaron en la Reconquista, y en concreto en los Riquelme.

Los Riquelme se van a unir con otras familias de gran prestigio de las oligarquía urbana $^{27}$ para reforzar este concepto de linaje lustroso y prestigioso. Se juntaran con el

24 En la rama de los Riquelme que participó en la conquista de Jerez de la Frontera y se instaló allí encontramos otra palacio de similares características. Ver el artículo de ANDÚJAR GALLEGO, M ${ }^{\mathrm{a}}$ CARMEN, «El palacio Riquelme: Expediente de declaración de B.I.C.», Revista de Historia de Jerez, 9, 2003, pp. 219-240.

25 Esta casa de los Riquelme iba a ser restaurada en 1888 por el arquitecto Juan Antonio Alcaraz Sánchez, en la cual se decía que había una gran barandilla. En 1967 es demolida y estuvo mucho tiempo desmontada en la Plaza de San Andrés. En la actualidad se ha colocado en la portada lateral del Museo Salzillo.

26 Ha habido autores que han establecido alguna semejanza entre el palacio Riquelme y el «Palacio de Herodes» del belén de Salzillo, el cual fue patrocinado en el s. XVIII por Jesualdo Riquelme y Fontes. A pesar de la relación del «Palacio de Herodes» con el barroco cortesano internacional y madrileño, la bibliografía local ha destacado su conexión con la mansión de los Riquelme de Murcia (conocida la fachada de la casa Riquelme, Soto ha insistido en este parentesco: SOTO BELTRÁN, M.D., «Iconografía del Belén de Francisco Salzillo», Verdolay, 5, pp. 219-230, cita pp. 229-230. En otros estudios se remarca también la condición murciana de su morfología, TORRES FONTES, J., Museo Salzillo, Madrid, 1959, p. 86; y PARDO CANALIS, E., Francisco Salzillo, $2^{\mathrm{a}}$ edic., Madrid, 1983, p. 38). Evidentemente hay similitudes en la ordenación de vanos, la presencia del balcón principal sobre un acceso toscazo, pero participa de la magnificiencia de un modelo más cosmopolita. Ver DE LA PEÑA VELASCO, C., «Escenografías arquitectónicas en el Belén. De lo castizo a lo cortesano», en Il Presepio di Salzillo. Fantasia Hispánica di natale, Esposizione nel braccio di Carlo Magno, Città del Vaticano, 12 febbraio/11 marzo, 1999.

27 Aquí sólo presentamos el enlace de los Riquelme con algunos de los apellidos que representan a estas familias, como muestra significativa; ya que se juntan con otras familias de gran renombre. Ver PÉREZ GARCIA, M., Ob. cit., 2004; FONTES FUSTER, E., Ob. cit., 1936; y DE LA VALGOMA DÍAZ-VALERA, D., Ob. Cit., 1956. 
apellido Fontes, cuyas alianzas matrimoniales con los Riquelme van a ser una constante e incluso con ello, si cabe, se dotará al linaje de más prestigio.

La familia Fontes (futuros Marqueses de Torre Pacheco ${ }^{28}$ ), relacionada posteriormente con los apellidos Caro $^{29}$ (futuros Marqueses de la Romana), Roca ${ }^{30}$ (futuros Marqueses de Malferit) y Bienvengud ${ }^{31}$, el linaje Riquelme va a estar emparentado con familias de gran prestigio, gozando la mayoría, como queda reflejado, de títulos nobiliarios ${ }^{32}$.

La familia Riquelme nunca va a olvidar de apremiar a los suyos, preponderando la línea vertical, es decir, la troncalidad del linaje; aunque no va a desdeñar la línea horizontal, en donde hay una extensa parentela, como hemos visto, que dota de prestigio y lustre social al linaje ${ }^{33}$. Así, hallamos el emblema de ambas familias, Riquelme-Fontes, en la casa palacio de dicha familia situada en la parroquia de S. Nicolás ${ }^{34}$. Aparece rematando

la fachada del palacio un escudo de armas partido en donde en un cuartel aparece el emblema de los Fontes y en otro el de los Riquelme.

Igualmente encontramos el emblema de los Riquelme en el enterramiento familiar situado en una capilla del Convento de S. Francisco ${ }^{35}$.

28 Archivo Histórico Nacional (A.H.N.), Sección (Secc.) Consejos, Leg. 8957, nº 47.

29 A.H.N. Secc. Órdenes Militares (OOMM), Montesa, Leg. 84, año 1757 (Pruebas de caballeros de Carlos Caro Fontes). El escudo de armas y apellido de Caro aparece en la parroquia de Santa María de Elche. Es un escudo en campo de oro, con un brazo armado de sable, saliente del flanco siniestro, con una espada de plata en la mano.

30 A.H.N. Secc. OOMM (Montesa), Leg. 86, 1757 (Pruebas de caballeros de Pedro Caro Fontes). El escudo de armas de los Roca se halla en la casa morada de D. Pedro Roca, en Valencia, Partido de Marchelones de los Arrabales. Escudo compuesto de un Roque a modo y forma de ajedrez de este nombre, en el centro un águila que con sus alas y piernas tendidas con dos cuellos separados mantiene sobre sus cabezas una corona. Las mismas armas se hallan en el oratorio de D. Carlos Roca, Marqués de Malferit. Esta descripción del escudo de los Roca de Valencia presenta algunas modificaciones con el escudo que presentamos en el presente trabajo, ya que no hemos podido encontrar el escudo que obedezca fielmente a esta descripción.

31 En la «Plazuela de Fontes» donde está la casa solas de este apellido, hay en la pared un escudo labrado en piedra: «La mitad a la izquierda partido en palo, y en la derecha tres barras, y encima de cada banda tres lises, y por orla ocho aspas». En la calle que de la puerta que llaman del porcel va al convento de las capuchinas; y en la casa solar de Bienvengud, sobre la puerta un escudo labrado en piedra: «Cuatro cuarteles en el primero de arriba una flor de lis, en el segundo ¿2 manos?, en el tercero bastones, y en el cuarto un león». En A.H.N. Secc. OOMM (Montesa), Leg. 86, año 1757. Sobre el palacio Fontes ver el libro Rehabilitación del Palacio Fontes, coordinación ejecutiva CRUZ, GEGARDO, Murcia: Confederación Hidrográfica del Segura, 1991, pp. 89.

32 Ver las obras de FONTES FUSTER, E., Ob. Cit., 1936; DE LA VALGOMA Y DÍAZ-VALERA, D., Ob. Cit. 1957; y el artículo de TORRES FONTES, J., «Nobiliario de los Fontes de Alonso Rodríguez de Almela», Murgetana, XCII, 1996.

33 Ver el artículo de HERNÁNDEZ FRANCO, J. y PEÑAFIEL RAMÓN, A., «Parentesco, linaje y mayorazgo en una ciudad mediterránea: Murcia (ss. XV-XVIII), Hispania, LVIII/1, 198, pp. 157-183.

34 Archivo Histórico Provincial de Murcia, Inventario y Partición de bienes de Antonio Riquelme y Fontes, Esc. Deogracias Serrano, 1839, p. 4961.

35 CASCALES, F., Ob. Cit., 1980. 


\section{BLASONES DE LOS LINAJES RELACIONADOS CON LA \\ FAMILIA RIQUELME}

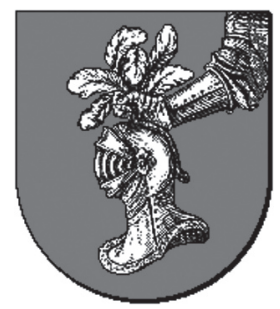

(Escudo de armas de los Riquelme)

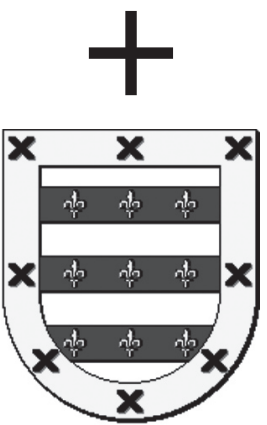

(Escudo de armas de los Fontes)

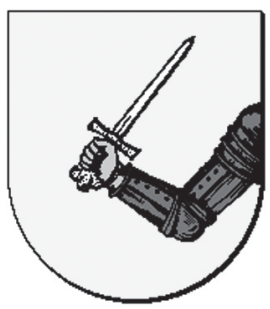

(Escudo de armas de los Caro)

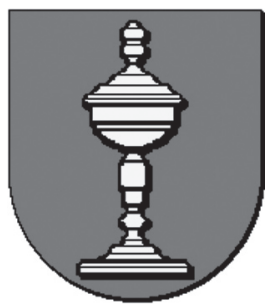

(Escudo de armas de los Roca)

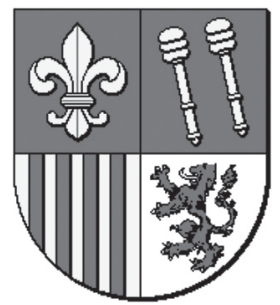

(Escudo de armas de los Bienvengud) 


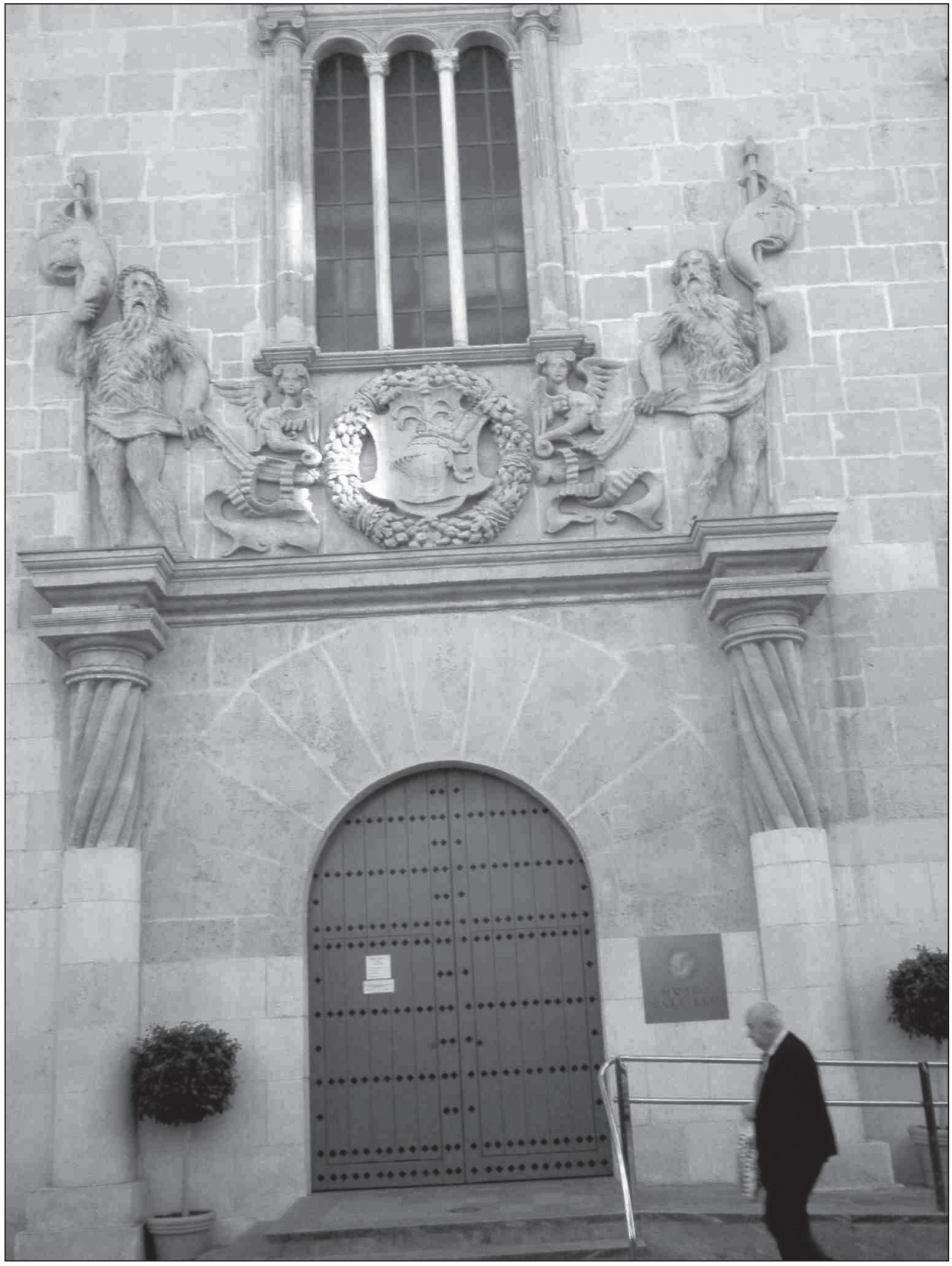

Portada del Palacio Riquelme, antiguamente situado en la calle Jabonerías (parroquia de San Bartolomé). Actualmente situado en el museo Salzillo. 


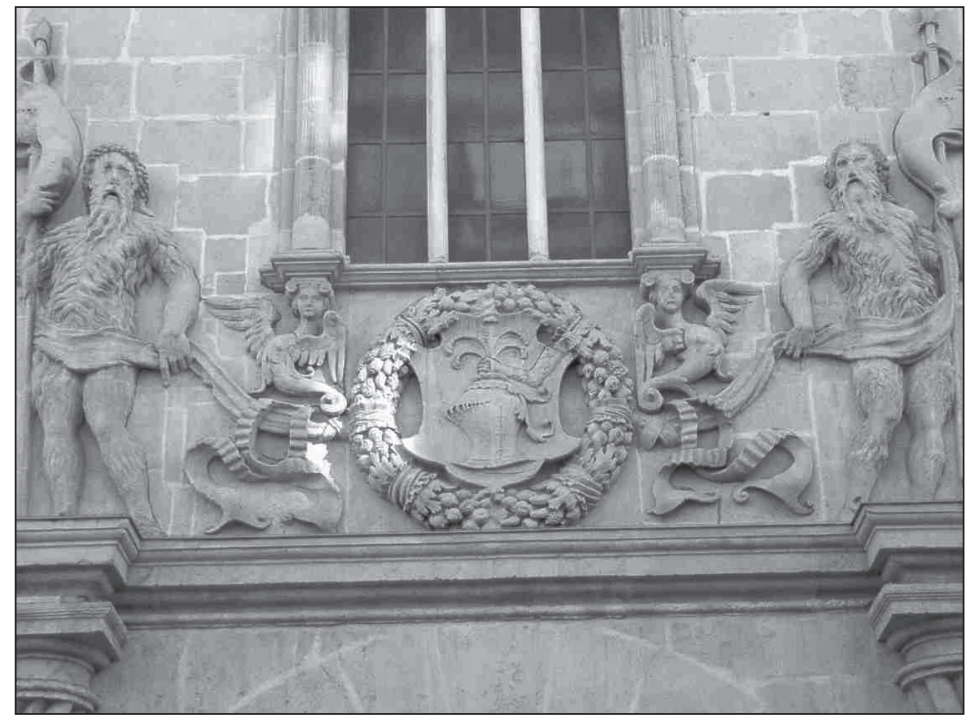

Escudo de armas de los Riquelme colocado en la fachada de su palacio.

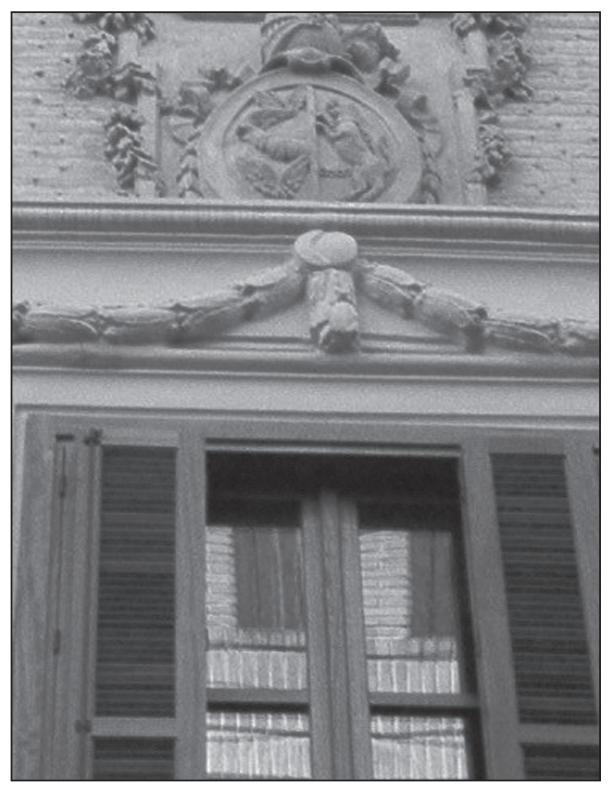

Escudo de Armas de la Familia Riquelme-Fontes que remata la fachada de su Casa Palacio de la parroquia de San Nicolás. 


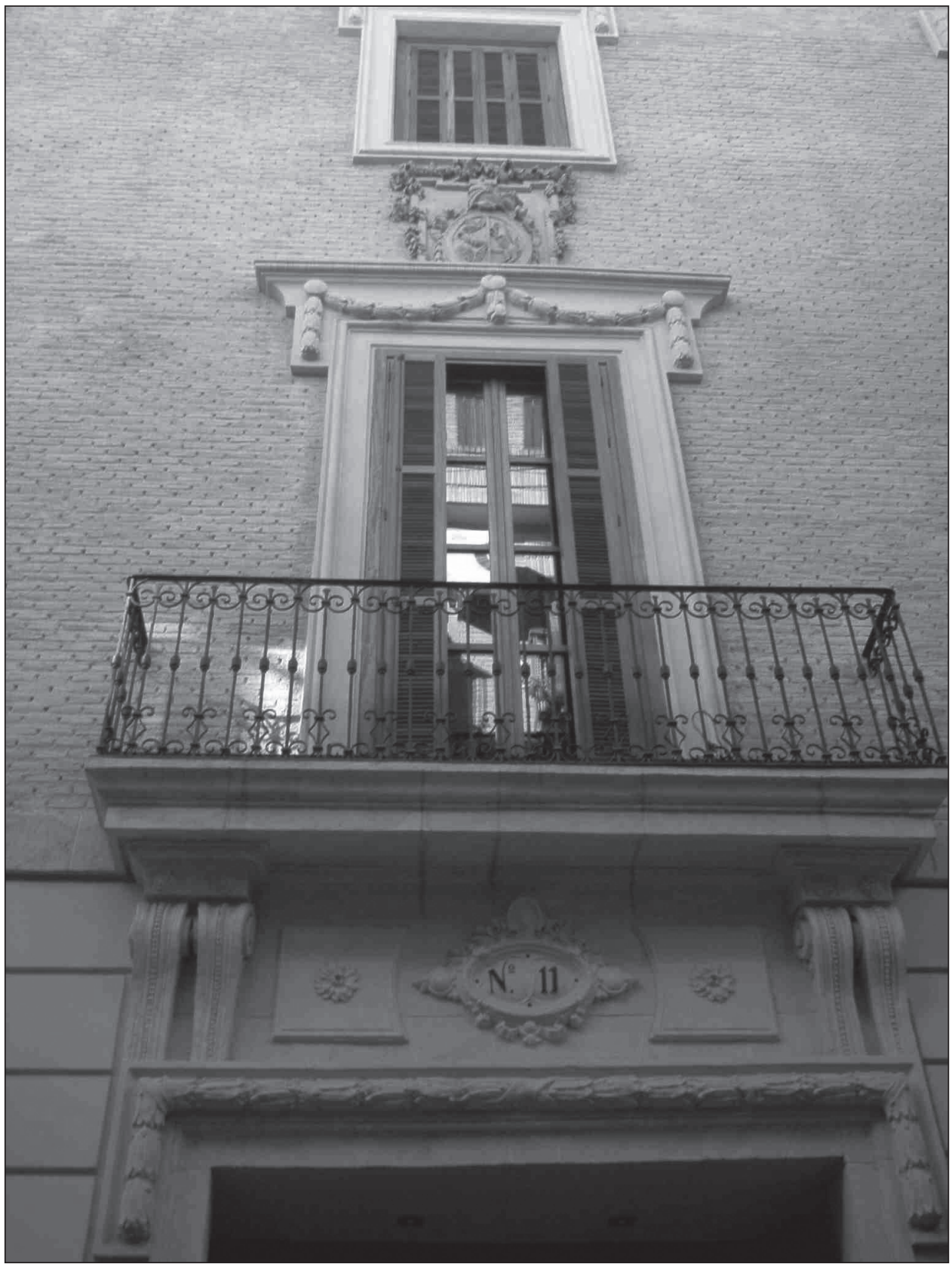

Casa Palacio de la Familia Riquelme-Fontes situada en la parroquia de San Nicolás. 


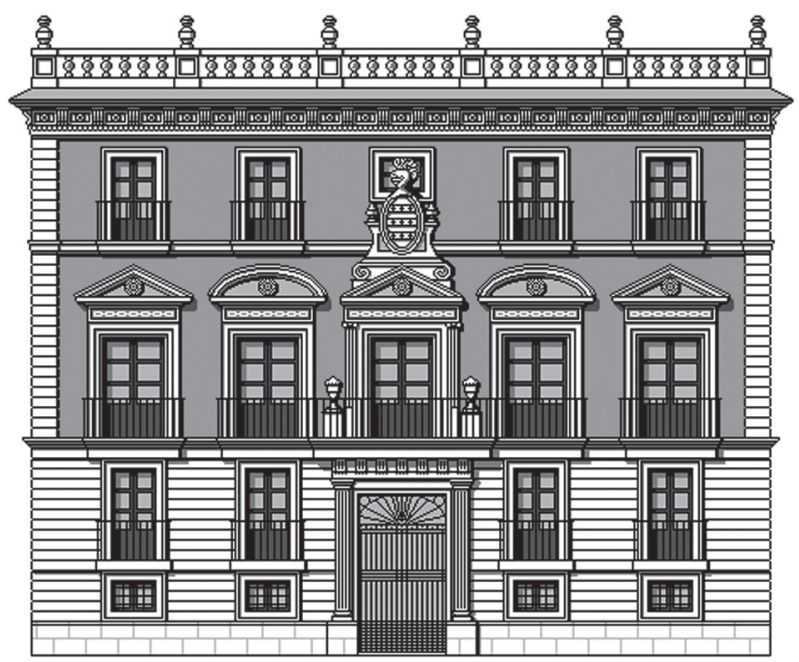

Palacio Fontes-Ordoño, en la calle Capuchinas. Estilo neoclásico, finales del siglo XVIII, demolido en la década de 1970. Dibujo L. Navarro.

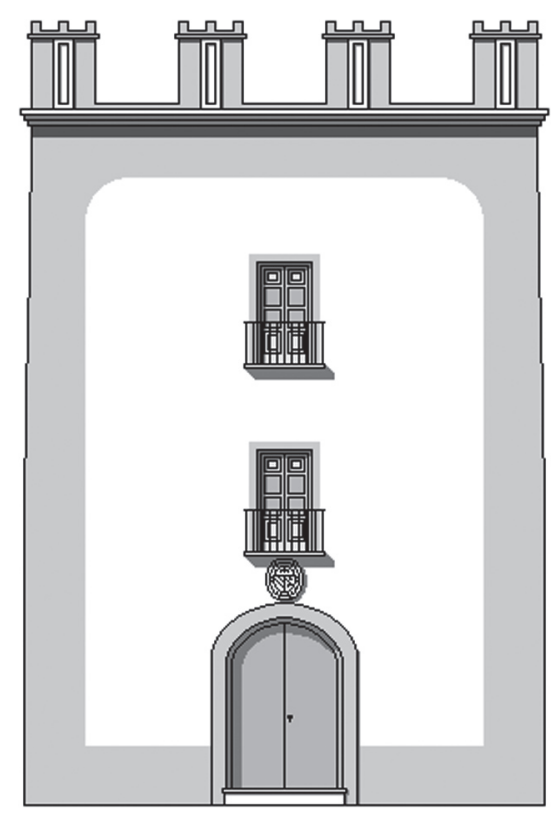

Conocida como torre del Rame o Rami, propiedad del Vínculo de los Bienvengud, Señorío de Hoyamorena, en el campo de Cartagena, recaído en la Casa Fontes-Ordoño. Dibujo L. Navarro. 


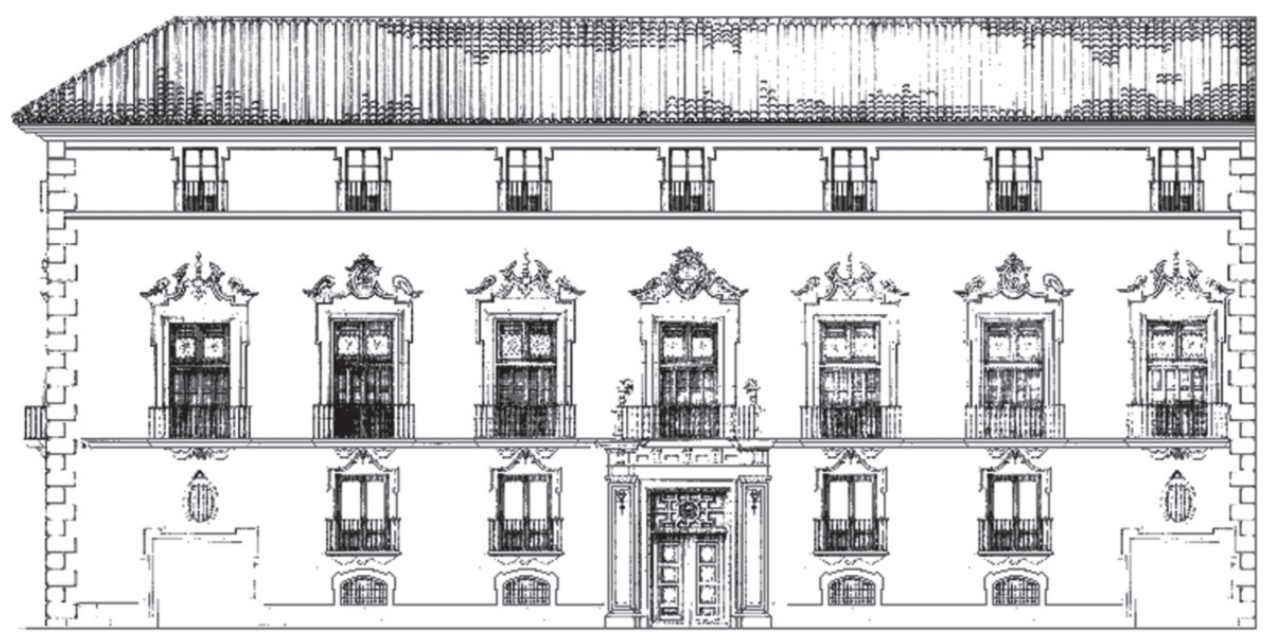

Palacio de los Marqueses de Torre-Pacheco, en la plaza Fontes de Murcia. Estilo barroco, mediados del siglo XVIIII. Actual sede de la Confederación Hidrográfica del Segura. Dibujo Juan A. Gómez de las Heras. 


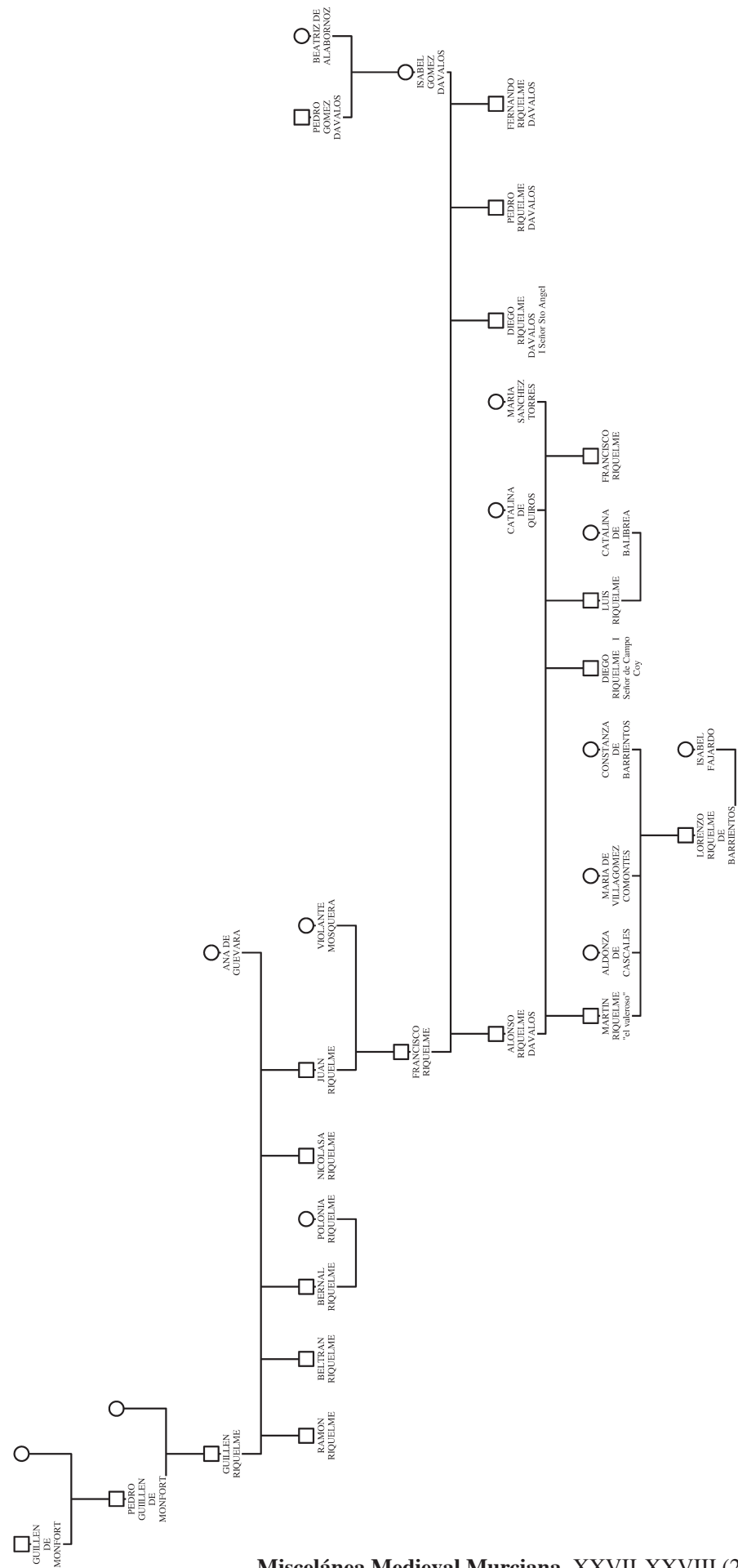


